\title{
Knowledge Status of X-Ray Department Managers of Istanbul Private Hospitals about Hospital Accreditation
}

\author{
Nuran Akyurt ${ }^{1, *}$ \\ ${ }^{1}$ Marmara University, Vocational School of Health Services, D-100 Güney Yanyolu Üzeri, Cevizli \\ Mahallesi, 34865 Kartal - Istanbul, Turkey
}

\begin{abstract}
JCI accreditation standards are an undertaking that provides continuity of improvement and development work that is guided by the development of patient care quality at the most appropriate level, the provision of a reliable patient care environment, and the reduction of the risks of patient and service providers. The purpose of our work is to determine the extent to which x-ray department managers from the Istanbul city's private hospitals who are preparing for accreditation or have successfully completed the accreditation can apply the JCI accreditation standards, their knowledge level and their attitude about it. The study's universe constitutes a total of 111 people serving as managers in the radiology departments of private hospitals operating in the province of Istanbul. A survey form was applied in the study. As a result, the education of the managers of the radiology services should be under the management of the persons with the expertise and experience.
\end{abstract}

\section{Accreditation in health organizations}

In the world countries, recent developments and changes in health sector have caused significant changes in the physical and functional structure of developed country hospitals. Medical technology, developed for the diagnosis and treatment of disease as well as for the protection of patients from disease has led to a decrease in hospitalization times for patients admitted to bedside services and an increase in bed turnover rates. This change affects the structure of the hospital, its design and functions, and provides a quality health care service in a very short time.

The health sector is an important sector around the world where, for a long time, standards and models have been launched based on the continual notion of improvement. Increased healthcare spending, gained importance of patient safety and continuous development idea at service providers and service receivers have led to healthcare organizations establishing quality management systems, applying international standards and constantly improving mechanisms.

* Corresponding author: nakyurt@hotmail.com 
In order to satisfy patients' need for medical care at a satisfactory level, efforts to provide quality services that have started in private hospitals and in a short time also applied in public hospitals are at the level of documenting the quality of health care services by an impartial external body.

The need to document the quality of health care services by an impartial external organization has emerged in the United States (USA) for the first time. The accreditation document for the health organizations operating in the USA started to be given by the "Joint Commission Accreditation For Health Organization" (JCAHO). This development in the field of health in the USA, has been a study that attracts the attention of world countries since 1990. Hospital accreditation in the international arena is made by Joint Commission International (JCI), a subdivision of JCAHO. Joint Commission International (JCI) works to improve patient safety and quality of health care in the international community by offering education, publications, advisory services, and international accreditation and certification. In more than 100 countries, JCI partners with hospitals, clinics, and academic medical centers; health systems and agencies; government ministries; academia; and international advocates to promote rigorous standards of care and to provide solutions for achieving peak performance.

Within health services, hospitals have always had a special place, as most of the resources in the entire service chain are consumed in hospitals. Approximately $40 \%$ of the expenditures in the Ministry of Health budget in our country are always allocated to hospital services. In this case, hospitals are obliged to place principles such as efficiency, activity and equity in health care. In particular, resources for in-hospital patients and advanced laboratory tests have two major impacts on hospital costs. For this reason, developed countries make great efforts to minimize hospital stay, to improve the success and to increase the number of the outpatient clinics and to avoid unnecessary laboratory use, [1].

Patients who do not need close supervision by the doctor or nursing care are closely followed in the hostels, which are built adjacent to the hospital. The purpose of these applications is to improve the quality of service provided to the patient and to reduce health expenditures, [2]. Providing quality goods or services is cheaper than what is known. Considering the sum of all income earned in the countries, the high spending on health care for many governments makes it difficult to control hospital costs and to implement health system reforms, [3]. Considering the situation in our country, the following should be taken into account: the rapid increase in the number of private hospitals over the last five years, the growing importance of health for the citizens and their families and the expectation of qualified health services.

Parallel to the developments in the world, important steps on accreditation are also being taken in our country. The Turkish Accreditation Authority (TURKAK) was established with the Law No. 4457 published on November 4, 1999 in order to accredit the conformity assessment activities in our country, [4]. In order to establish the "National Health Accreditation System", the Ministry of Health initiated a series of studies under the health transformation project. In these studies conducted under the leadership of the Ministry of Health, great importance is attached to the participation of all stakeholders in the health sector and the international experience in this area, [5]. As the Ministry of Health, negotiations are underway with the Joint Commission International (JCI) regarding the establishment of the National Health Accreditation System (Institutional Evaluation Hospital Accreditation System). The business alliance, which started with Joint Commission International (JCI), took concrete steps in structuring the National Accreditation System, assessed the situation in different working groups, and signed a protocol with JCI officials in 2004, [6]. Ministry of Health and JCI business association protocol includes the structuring of the national health accreditation system, the 
development of standards, quality and monitoring systems, the training of auditors and the creation of databases.

\section{International accreditation standards in hospitals}

JCI accreditation audit process is seen as an assessing of general policies and values of the hospital, organization structure, service activities, services provided, environmental management, communication network, information use, operational policies, employee skills and training, and quality management.

There is experiences that a two-year preparatory process is needed (preparing for the standards and transitional stages) for hospitals in order to get accredited from JCI, [7]. Hospitals have to form "councils and committees" within their own organization to implement and oversee 440 standards that the JCI organization has collected under 11 main headings.

The hospital needs to establish its mission, vision, policies and strategies before entering the JCI accreditation audit. After the mission and vision of the institution is determined, there are opinions that the institution should set a number of goals and targets that will guide the strategies for the future and help them to be measured and assessed, [8]. After the missions, vision and strategies that the hospital management has established, it is necessary to establish "quality improvement council" in order to determine "quality indicators follow-up procedures" for JCI accreditation standards and measurable elements and to follow them.

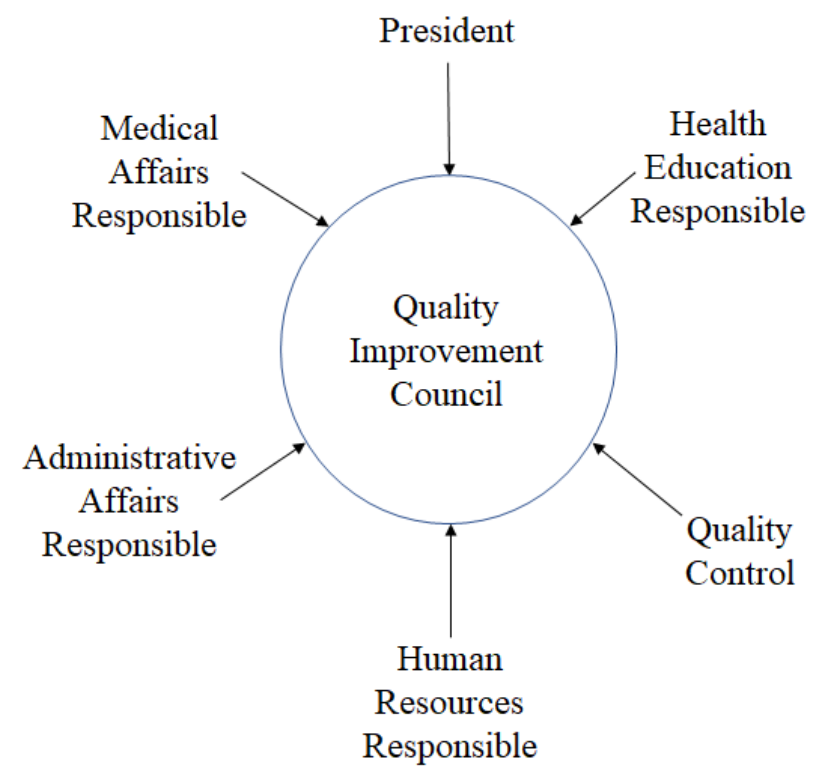

Figure 2.2: Structure of the Quality Improvement Council

Source: Mücella Tokatlığlu, “Uluslararası Akreditasyon Standartları”, IQ Uluslararası

Kalite Danışmanlık Organizasyon AŞ Dokümanları, p. 250.

There are views on the necessity of using guidelines in clinical practice in order to collect, analyze and continuously improve the data of clinical and administrative 
procedures designed to provide quality patient care within the scope of the hospital's mission, vision and quality management improvement goals, $[9,10]$.

Follow-up procedures should be established in order to evaluate the services provided by the hospitals. These follow-up procedures show the result of a time-out or outcome performance of all efforts and processes undertaken to realize the mission, vision and policies of the hospital. Planned by the quality management council, prepared in line with the quality management and improvement program, units in the scope of specific strategic follow-up and reporting plan of the departments within the flow of the quality indicator follow-up procedure have to determine the processes they consider to follow, the quality indicators and their targets. The quality council and the leaders determine which processes should be monitored and improved on a priority basis, the priority and the frequency of data collection. These priorities should include critical, high-risk and problem-prone areas. Today, there is a great increase in the medical information, with the technology development in measuring and imaging methods, medical tests, analysis and monitoring devices, also in data and information gathered from individuals and patients. In an environment where the level of knowledge of individuals is high, patient protection methods are in the foreground, the context of fast and effective treatment is of high expectations and institutions are increasingly specialized, it is now one of the priority requirements to receive care services in different phases as integrated and continuous services. The condition of the patient, radiological requirements and interventions depend on the ability of the hospital which has fully implemented the informational strategies.

Hospital management, requesting JCI accreditation is required to establish the quality management program for the radiology department so that the accreditation standards can be used and applied. With the participation of the radiology department manager (leader), "strategy and reporting follow-up process" for the department should first be prepared. Radiology manager should show all services in the department during the strategy and reporting follow-up process. In the strategy follow-up process, the radiology department should detail its aim, vision, mission, goals, measurements needed to achieve these goals, and specific performance criteria for the segmentation.

\section{Methods}

The purpose of our work is to determine the extent to which x-ray department managers from the Istanbul city's private hospitals who are preparing for accreditation or have successfully completed the accreditation can apply the JCI accreditation standards, their knowledge level and their attitude about it.

\subsection{Universe and sampling}

The study's universe constitutes a total of 111 people serving as managers in the radiology departments of private hospitals operating in the province of Istanbul. Scientific data related to the hospitals were prepared taking into account the "Statistical Yearbook of Hospitalized Treatment Institutions" published by the Ministry of Health.

\subsection{Data collection tools}

Research is a descriptive work. Survey form was created and applied in the survey. The accreditation standards developed by the JCI accreditation organization for radiology departments were taken as basis in the creation of the statements in the questionnaire, [11]. For the statements in the questionnaire, the 13 standards and measurable components 
prepared for these standards which were defined by JCI accreditation organization (patient evaluating) for evaluating radiology services were used, [12].

The accreditation standards for the radiology departments of the JCI organization are as shown below. These standards are, [13];

HD.6 Radiology services are available to meet the needs of patients and they must comply with all regional / national standards, laws and regulations.

HD.6.1 Diagnostic imaging services must be provided by the institution or linked to external resources that are ready for use at any time.

HD.6.2 The radiation protection program should be available, followed and documented.

D.6.3 The implementation and interpretation of the tests should be carried out by appropriately trained, competent and experienced specialists.

HD.6.4 Radiology results should be given within a period defined by the institution.

HD.6.5 All radiology equipment should be regularly checked, maintained, calibrated and kept in a register of these activities.

HD.6.6 X-ray films and other materials should be available on a regular basis.

HD.6.7 The management of diagnostic radiology services should be the responsibility of the expert (s).

HD.6.8 Quality control procedures should be established, followed and documented.

HD.6.9 The institution should regularly check the quality control results of the products coming to the radiology service from outside.

HD.6.10 The institution should have the necessary infrastructure to be able to apply to specialists in highly specialized diagnostic areas.

HD.7 Patient-care medical, nursing and other persons and services must be in a business alliance to analyze and integrate patient assessment.

HD.7.1 The most urgent and important maintenance needs must be identified.

In the first part of the questionnaire, there are questions about determining the demographic information of the managers in the radiology departments.

In the second part of the questionnaire, there are questions about the departments of radiology managers.

In the third part of the questionnaire, we tried to determine the JCI standards developed for the evaluation of the services provided in the radiology departments of the hospitals, which would mainly require accreditation supervision, and the participation rates in the areas that managers should comply with when fulfilling them.

\subsection{Analysis of data}

The obtained data were analyzed by using SPSS data analysis program. As statistical analysis technique, $[14,15,16,17,18]$; Frequency distribution, Independent Sampling tTest, One-Way ANOVA and Tukey Multiple Comparison Method (Post-Hoc) were used. 


\section{Results}

When we examined the results, $29.7 \%$ of the 111 radiology managers participated in the survey were women, $70.3 \%$ were men; $44.3 \%$ of them are working as managers for $0-5$ years; $44,1 \%$ are radiologists, $43,2 \%$ are vocational school of health graduates and $12,7 \%$ are vocational high school graduates.

When we examined the results of the questions concerning the departments, it was found that $57.1 \%(\mathrm{n}=28)$ of them had a quality certificate, $24.5 \%(\mathrm{n}=12)$ of this certificate had ISO 9001 quality certificate and 14.3\% $(\mathrm{n}=7)$ documented that they are documentary. Do you have a vision and mission in your department and they have answered with $61.2 \%(\mathrm{n}=30)$ yes of them.

When we examine the answers to the accreditation criteria of the radiology departments of hospitals seeking to be accredited, I agree with $45.9 \%(n=51)$ of the expression "radiology services are available to meet the needs of HD 6 patients and they must comply with all regional / national standards, laws and regulations" , 43.2\% $(\mathrm{n}=48)$ completely agree with each other. Since the unit is on institutions Turkey Atomic Energy Agency (TAEK) is operated under license from operating certificate issued by the phrase to agree $28.2 \%(\mathrm{n}=31)$ I totally agree $71.8 \%(\mathrm{n}=79)$ percent gave the answer, "HD.6.6 X-ray films and other materials for use as a regular $53.6 \%(n=59)$ agree completely, $31.9 \%(n=35)$ agree completely. For the failure of the radiology services, X-ray films have been participated at high level since the purchase of X-ray films has to be well followed up from the storage to the storage, as well as to the presentation of the extraction rooms.

Also we aim to determine the consistency of the statements made by us with respect to the accreditation standards, to evaluate the homogeneity by subjecting it to reliability analysis and different statistical tests. The Cronbach Alpha value was calculated to determine the reliability of the data obtained by the questionnaire. We can say that our questionnaire is reliable since alpha values are very close to 1.00 , which is considered as full reliability.

\section{Discussion}

"Accreditation"; is a formal process by which a health facility conforms to preestablished and published standards, which are evaluated and approved by the JCI accreditation organization. The decision on accreditation of a specific health institution is made after an on-site audit by accreditation auditors.

There is a difference of opinion between educational status and age groups in the extent to which JCI accreditation standards are fulfilled by those who have assumed the role of manager in the radiology units of private hospitals. The difference of opinion among the managers regarding these standards lies between the young group managers (the newly completed group of specialization / university education) and the age group who have been for many years serving in the radiology units and are in the pension stage. In these two age groups, radiology specialist managers over 45 years old have had a more positive view of their implementation in the parts of accreditation standards. The same situation has also been observed among the radiology specialists who have successfully completed speciality medicine and the radiology department graduates of the vocational school of health. While the radiology specialist gives a more positive opinion in the fulfillment and implementation of some JCI standards, the vocational college graduate thinks differently. This is also seen between managers of the vocational school of health services graduates and managers of the vocational high school graduates in the fulfillment and implementation of some JCI standards. In order to overcome the disparity between the education and age groups that we are trying to summarize above, the meaning of the JCI standards and how it should be 
applied/implemented in the radiology departments has to explained with trainings given by the experts of this subject. We think that this training about the standards can be regarded as a positive contribution to the elimination of differences of view and application.

\section{Conclusion}

Hospital accreditation is a vocational assessment and scorecard work carried out by professionals. In short, it certifies that the hospital radiology services that have received the accreditation document are also provided at a desirable level, that is, it is committed that the employees' opinions are valued, the safety and security of the patients and employees are provided, the team work is emphasized and the professional education and progress of the employees are supported.

The accreditation standards developed by the JCI organization for the radiology department include the staff, the patients and their relatives, and the safe operation of the functioning devices in the department. The standards established by the JCI organization for the radiology departments are based on national, international laws and regulations. Therefore, in order to perform ideal radiology services in private hospitals radiology managers who have fulfilled the requirements of the JCI accreditation standards have also fulfilled the ideal radiology service. In short, we believe that ideal radiology services can be provided with ideal radiology units that protect patients and employees, respect patient rights, inform patients, have calibrated all the devices actively used, and take into account other issues that we have already mentioned. As a result of our work, the requirements for hospital management and radiology managers who wants to be accredited by the JCI organization are listed as a suggestion.

\subsection{Suggestions}

- Radiology managers should be able to create organizational charts for their departments including the competency and responsibilities of the employees.

- Radiology managers need to create a device management program for all devices in their units. This program should contain all information about the devices. It is necessary to use specialist experts in selecting and purchasing radiology devices. In the accreditation process, formal entry of radiology devices becomes important.

- Hospital senior management must regularly document records of radiology devices. For this purpose, medical physicians should be employed in the units.

- The hospital senior management is required to set up units to carry out periodic maintenance and repair and calibration plans of all medical and radiological devices. Calibration procedures for all devices in the hospital must be followed by biomedical engineering. The biomedical departments of the hospital should create a staff planning to coordinate with these, the established plans for the medical devices.

- Calibrations of mammography, computerized tomography, magnetic resonance imaging (MRI), nuclear medicine, etc. devices from the radiology departments should be performed using phantoms approved by international organizations. It is necessary to make quality measurements for the acquired image and to keep records for radiology management.

- Instructions should be made by the administrators regarding the storage and service of the kit, film and other materials used in the radiology units and the materials should be shipped in accordance with this instruction (instructions for storing radiology materials). 
- In situations such as fluoroscopic procedures used in radiology units, catheter guidance in angiography units, the x-ray machine should be used as short as possible. Radiology managers should refer to x-ray attenuation methods in such cases.

- Radiology managers should be able to provide personal protection for employees by ensuring that personnel working in the units are provided with eyes protection, thyroid protective accessories, lead, glass plate, lead screen, lead gloves, gonod protectors and lead aprons.

- Lead aprons, lead curtains, lead gloves, gonod protectors and thyroid protectors used for the purpose of protecting the radiology workers and their patients should be checked at least once a year for cracks, holes or tears under fluoroscopy and these procedures should be recorded.

- Before starting the radiological examination, it is necessary to develop and implement a method for obtaining the written confirmation form of the patient, which provides the accuracy of the patient's identity information and the information of the requesting patient and the patients who have special circumstances, especially in the units where the interventional procedures are performed.

- Before starting the radiological examination, especially in the units where the interventional procedures are performed, it is necessary to develop and implement a method which provides the accuracy of the patient's identity information with the identity information on the request sheet and which obtain the written consent form from patients with special circumstances.

- Patient preparation instructions should be drawn up for all examinations to be made in radiology units and personnel should be trained about these instructions.

- Radiology managers need to establish a follow-up process to identify processes that are problematic or potentially problematic in order to improve the radiological services provided in their departments.

- Radiology managers need to apply the shift system to increase the usage capacities of the medical devices used in the units and to keep them active 24 hours a day. Accordingly, rotation plans for the personnel in the shift system must be established. Radiology services should be provided for emergency services except working hours.

- Radiology administrators should create an operational program that allows them to monitor the performance of their departments on a regular basis, to review test results and to track material flow on a regular basis, and periodically document records associated with this program.

- Radiology managers should identify specialists who will be needed in specific diagnostic areas, such as radiation physics, nuclear medicine radiation oncology, where appropriate, and determine a method to be able to contact them any time.

- There should be an active radiation safety program at the level required by the risks / hazards encountered / may encountered throughout the hospital. The program should specify safety practices and preventive measures for the radiology team, other teams and patients. The program should be coordinated with the institution's safety management program.

- Reliable quality control systems need to be established to provide excellent radiology services in radiology units.

- Radiology managers should be able to ensure that all devices operate at acceptable levels and are safe for the user (radiology personnel).

- In order to make a decision for recruiting, the radiology managers should organize orientation training and rotation for new personnel where they should make different 
number of shots in different radiology units. The managers should support all its employees in recruitment, training, development and continuing education programs.

- Radiology managers should organize continuing education programs in relation to the services they provide to their staff and patients. They should create a budget for annual scientific activities for the staff of the department and direct their staff to this activities.

- Radiology managers should be able to create a team-based, mutually respectful environment for all of their employees.

- Radiology managers should be able to take measures to reduce bureaucracy in the department. Radiology managers should be able to conduct internal and external researches on patient expectations.

- Radiology managers should be able to create mechanisms for facilitating new ideas about the department (suggestion boxes, awarding of best ideas, etc.).

- Radiology administrators should be able to create procedures and instructions for all radiological examinations performed in their units and ensure that all employees are properly trained in this area.

- In interventional radiological procedures, radiology managers should be able to include the patient, patient family and persons who decides in behalf of the patient in the decision process.

- Radiology managers need to establish a method to ensure that information (patient datas) of patients arriving at the units to be examined is kept properly.

- Radiology managers should lead the creation of a safety committee based on the size of the hospital they are working in, and should take part in the execution of the program.

- Valuable data should be provided to monitor all aspects of the program, to develop the program, and to reduce the probability of risks within the organization.

\section{References}

1. Haydar Sur, "Hastanelerde Kaynak İsrafi: Nasıl Önüne Geçmeli?” (Çevrimiçi) http://www.merih.net/m1/0mangmt.html, (30 Kasim 2006).

2. Murat Yerebakan, Özel Hastaneler Araştırması Mevcut Durum Sorunlar ve Çözüm Önerileri, İstanbul Ticaret Odası Yayın No: 2000-26, , s.46 (İstanbul 2000).

3. R. L. Williams, “JCAHO Accreditation. Is It Necessary?”, Nurs Manage, Nov, 28(11), pp. 60-63 (1997).

4. http://www.turkak.org.tr/literat/mkl1.html, (Çevrimiçi), (16 Agustos 2004).

5. George Purvis, "Kurumsal Değerlendirme Hastane Akreditasyon Sistemi" raporu, Kalite ve Akreditasyon Çalıştayı (Antalya), JCI International Summer Practicum on Quality Improvement and Accredidation, 12-16 Temmuz 2004; Sağlık Hizmetlerinde Akreditasyon, 23 Eylül 2004, JCI ile işbirliği anlaşması (İstanbul); Sağlık Hizmetlerinde Kalite ve Akreditasyon, Bursa (18 Aralık 2004).

6. Recep Akdağ, "Sağlı Sektöründe Akraditasyon" (Çevrimiçi) http://www.akreditasyon2004.org/pdf/Bakan.pdf, (22 Ekim 2004).

7. İrem Ergun Öcal, "JCI Standartları ve Uluslararası Kalite”, SB Diyalog, s. 30 (Eylül 2005).

8. Hayri Ülgen, S. Kadri Mirze, İşletmelerde Stratejik Yönetim, Literatür Yayınları No:113, s. 69 (2004, Ocak). 
9. A. A. Boxwala, S. W. Tu, M. Peleg, Q. Zeng, O. Ogunyemi, R. A. Greenes, et. al., "Toward a representation format for sharable clinical guidelines", J Biomed Inform, 34 (3), p. 157 (2001 Jun).

10. S. T. M. Shaneyfelt, M. F. Mayo-Smith, J. Rothwangl, "Are Guidelines Following Guidelines? The Methodological Quality of Clinical Practice Guidelines in The Peer Reviewed Medical Literature", Journal of the American Medical Association (JAMA), 281, p. 1902, (1999).

11. Uluslararası Birleşik Komisyon, Hastaneler için Akreditasyon Standartları, s. 56-61.

12. A. e., s. 41-63.

13. Joint Commission International (JCI) Accreditation Standards for Hospitals, Effective, 2. Edition, pp. 45-46 ( January 2003).

14. Ayhan Ural, İbrahim Kılıç, Bilimsel Araştırma Süreci ve SPSS İle Veri Analizi, Detay Yayıncılık, Ankara, s. 151, 185, 172, 192 (Ocak 2005).

15. Yahşi Yazıcığlu, Samiye Erdoğan, SPSS Uygulamalı Bilimsel Araştırma Yöntemleri, Detay Yayınc1lık, Ankara, s. 203, 239, (Ocak 2005).

16. Remzi Altunışık, Recai Coşkun, Serkan Bayraktaroğlu, Engin Yıldırım, Sosyal Bilimlerde Araştırma Yöntemleri, SPSS Uygulamalı, Sakarya Kitabevi, Sakarya, s.318328, 114 (Ekim 2005).

17. Aziz Akgül, Osman Çevik, İstatiksel Analiz Teknikleri SPSS’te İşletme Yönetimi Uygulamaları, Emek Ofset Ltd. Şti., Ankara, s. 3, 170, 185, 434 (2005)

18. Nural Bekiroğlu, Açıklamalı Bioistatistik Terimleri Sözlüğü, Nobel Tıp Kitapevleri, İstanbul, s. 44 (1998). 